\title{
Combustion of Air-Sheathed Kerosene Spray Jets Stabilized in a Stagnation-Point Reverse Flow
}

\author{
Yukiya Arai, Takumi Saito, Takafumi Nakasu, Shigeru Hayashi \\ Hosei University \\ 3-7-2 Kajino-cho, Koganei-shi Tokyo, Japan \\ yukiya.arai.5r@stu.hosei.ac.jp; taku.ocean.311.zero@gmail.com; gooday19jp@gmail.com; hayashi@hosei.ac.jp
}

\section{Extended Abstract}

A new low-NOx combustion approach for liquid-fueled gas turbine combustors is proposed: coaxially surrounded by a non-swirling annular air jet, a fuel spray prepared by a pre-filming air-blast atomizer is injected toward the end wall of a cylindrical combustion chamber [1]. The resulting stagnation-point reverse flow in the dome provides a robust flame stabilization at fuel-lean conditions, especially near the flammability limit. This approach is essentially free from autoignition or flash back in the mixture preparation zone since evaporation of fuel spray and premixing of fuel vapor-air proceed in the combustion chamber. Low NOx emissions potential of this approach was assessed by using a model combustor, $82 \mathrm{~mm}$ in inner diameter and $240 \mathrm{~mm}$ in length, at inlet temperatures ranging from 373 to $573 \mathrm{~K}$ at atmospheric pressure over a range of overall equivalence ratios from 0.55 to 0.7. Single digits of NOx emissions were confirmed with complete combustion (efficiency greater than 99.9\%) at lower adiabatic flame temperatures. Atomization level of the spray was varied by changing the flow rate of air to the atomizer, $m_{\mathrm{a}}$, from 0.5 to $1.2 \mathrm{~g} / \mathrm{s}$ while the total air flow rate, $m_{\mathrm{o}}$, was kept constant at $7.2 \mathrm{~g} / \mathrm{s}$. The inner diameters of the nozzles for the outer air, atomizing air and for prefilming of fuel were $10.4,4.8$ and $2.4 \mathrm{~mm}$, respectively. The distance between the injector tip to the end wall, $L$, were set at 130,80 and 40 $\mathrm{mm}$. Global flame shape varied with atomization level depending on the distance. A frisform-shaped flame was established for longer $L$ and at higher atomization levels while a cone-shaped flame followed by a flared outer rim was in the region close to the end wall for shorter $L$ and at lower levels of atomization. The observed trend of NOx emissions with atomization level was unexpected: with increasing $m_{\mathrm{a}}$, the NOx emissions decreased to reach a minimum at $m_{\mathrm{a}}=0.75 \mathrm{~g} / \mathrm{s}$ and then increased. Direct flame images at different atomization levels showed that the leading edge of the flame came closer to the injector tip with increasing $m_{\mathrm{a}}$, or promoting atomization. High-speed images of Mie scattering by fuel droplets, $\mathrm{OH}$ and $\mathrm{CH}$ chemiluminescence were recorded to find out the regions where fuel droplets evaporate completely and where major reaction occurred. At higher level of atomization, fuel evaporation should be faster and therefore combustible mixtures can be easily prepared at positions closer to the injector exit. The premixing of fuel vapor with the outer air jet before entering the flame is poor because of the shorter mixing time, which may result in the formation of locally hot spots and higher NOx emissions. Some larger droplets with larger inertia can penetrate through the annular air sheath into the hot combustion products and ignite to burn. They can be a source of higher NOx emissions. At poor atomization case, fuel evaporation should be delayed and combustible mixture is formed at a point far from the injector tip. Some droplets remained incompletely vaporized when they reached the flame front, which may lead the higher NOx formation. This explanation is supported by high-speed images of Mie scattering by fuel droplets, $\mathrm{OH}$ and $\mathrm{CH}$ chemiluminescence corresponding to the combustion reactions.

\section{References}

[1] T. Saito, T. Nakasu, H. Yamada, S. Hayashi, "Emission Characteristics of Reverse-Jet Stabilized Non-Premixed Combustion of Liquid and Gaseous Fuels," in Proceedings of the European Combustion Meeting, Dubrovnik Croatia, TX, 2017. 